\title{
The Dynamic Roles Played by a Biochemist
}

\author{
S. P. Dandekar • A. M. Rishi
}

Received: 13 May 2014/ Accepted: 17 June 2014/Published online: 27 July 2014

(C) Association of Clinical Biochemists of India 2014

Biochemistry is probably the only basic science which has a gamut of ramifications. Apart from it being incorporated in areas such as Microbiology, Genetics, Physiology, Molecular Biology and others, it also comprises of areas such as plant biochemistry, animal biochemistry and medical biochemistry, to name a few. Biochemistry related to human health and diseases is known as medical/clinical biochemistry. Clinical chemistry involves the application of biochemical knowledge to medicine [1]. A biochemist has major roles to play in the professional life. The roles of a biochemist can be divided into three:

1. Role as an academician

2. Role as a laboratory professional and

3. Role as a researcher

According to Harden and Crosby [2], there are 12 roles that can be played by an academician. The six core ones being a facilitator, planner, information provider, role model, resource developer, and an assessor. As a facilitator, a teacher can be a mentor and learning facilitator to students. Encouraging and professionally grooming the students will prove useful. The responsibility of creating and producing resource and study material rests with the teacher. Curriculum planning, and course organization involves a carefully drafted strategy. It is important that the fundamental concepts are clarified right at the beginning of a lesson plan, for the student to comprehend a topic. Application of theoretical biochemical knowledge can be encouraged by using an integrated, interactive approach.

S. P. Dandekar $(\bowtie) \cdot$ A. M. Rishi

Department of Biochemistry, Seth G.S. Medical College and

K.E.M. Hospital, Parel, Mumbai, India

e-mail: suchetad@hotmail.com
E.g. Outlining biochemical events and correlating them with biochemical laboratory tests.

In order to be an information provider, teaching methodology needs to be given attention right from the undergraduate level. As suggested by Chickering and Gamson [3], to fulfil the seven roles of a teacher one should:

- encourage student-faculty contact,

- develop reciprocity and cooperation between students,

- encourage active learning

- give prompt feedback,

- emphasize time on task,

- communicate high expectations,

- respect diverse talent and ways of learning.

Thus we are now moving from being teacher centered to being learner centered.

Incorporation of new ideas and competencies which will help foster the academic development of students shall involve the role of the teacher as a resource developer. The current medical curriculum is heavily discipline based. Further, it is hardly under systematic review. Biochemistry curriculum should be aligned to the modern trends in biochemistry and laboratory medicine [4].

In the study carried out by Minasian-Batmanian et al. [5], undergraduate education should highlight the connection between the theoretical and clinical application. A habit of self-directed and life-long learning in the students should be inculcated. A core curriculum should be customized and be tailor-made to suit global as well as local needs.

Who can deny the fact that the teacher has to be a good role model? In our lives at some time or the other we have encountered a teacher who has inspired us. They have shaped many a person. 
Last but not the least, the role of a teacher in the assessment process cannot be denied. Right from the formative assessment to the summative assessment, the principles have to be effectively honed.

Laboratory is the domain where a clinical biochemist assumes a dual and interchangeable role of a researcher and a laboratorian. Diagnosis plays a very important part in primary health care centres. Method development is the principal force in clinical biochemistry. Focus should be given on pre-analytical, analytical, validation, and interpretation of test results. Post analytical issues too cannot be ignored. The concerned staff should be given appropriate training and also should be updated on the latest trends in the form of Continuing Medical Education programmes and seminars.

There is a tremendous increase in the requirements of laboratory diagnosis [6]. The healthcare sector is rapidly expanding and there is a swell in the array of laboratory tests provided. According to the study conducted by Plebani [7], in recent decades there has been a drastic change in the role of a laboratory professional, wherein emphasis is on analytical accuracy, test selection, and test interpretation. Involvement in therapeutic decisions, understanding of preventive measures rather than curative measures, shift from anecdotal care to evidence-based medicine, accompanied by increased awareness of knowledge and skill has contributed to this change.

The role of a biochemist must not be restricted to analytical aspects of the laboratory. There should be an active involvement in the institutional process development which includes guideline development, redesign of laboratory services, and application of patient satisfaction measures [8]. Increasing laboratory tests and complex healthcare environment has made it mandatory for the clinical information to be integrated with laboratory data.

Research can have an impact on the clinical laboratory. It is the responsibility of the clinical laboratory personnel to maintain the quality of the process. Ironically, advances in science and technology will increase the complexity of the system. Hence, there is a necessity to integrate the preferences of clinicians with valid and updated clinical research evidence.

Moving on to the third role played by the Biochemistthat of a researcher-research in biochemistry is presently undergoing a dynamic change. It is particularly interesting because it incorporates almost all areas of life sciences. Qualitative research with regards to laboratory processes is important as it will have an impact on the future of medicine. Evidence based medicine and translational research play a very important part in the whole scenario. Hence, the need of the hour is the availability of affordable tests with valid clinical outcomes. This makes us realise that there is still so much to be done.
The quest for new, effective biomarkers is always on. For instance, the recent discovery of new biomarkers for pancreatic and colon cancer brings to light the impact of improvising techniques. Biochemistry is the converging point for all fields in medicine. Physicians rely on biochemists to decide the course of treatment for patients.

The reason why many of us pick biochemistry as a career choice is to pursue research. According to Kilpatrick, valuable research can be carried out without having the hassle of large funding [9]. The only things young researchers need is a restless and innovative mind, and the ability to enjoy their work. With self-satisfaction being a bonus point, a researcher must not take away the spotlight from the main focus of the work, i.e., to give an account of the findings for betterment of the patients.

Kilpatrick laid down Seven Rules of Research [9]. These can be elaborated as:

- Don't be afraid of asking so called stupid questions

- Don't assume someone has already studied it

- If the question makes you curious, the chances are other people will also want to know the answer

- If the study looks difficult, try to think laterally

- Jump on unusual findings or promising leads

- Some of the most interesting studies are cheap to perform and last but not the least

- Get it published

Thus our discipline can continue to make a unique and relevant contribution to healthcare.

We are indeed in a very exciting era where we play the dynamic roles of a teacher, laboratorian and that of a researcher.

Make the most of this opportunity!!

\section{References}

1. Krishnaraj R. The place of biochemistry in veterinary education and research. Biochem Educ. 1979;7(1):11-2.

2. Harden RM, Crosby JR. AMEE Guide No 20: the good teacher is more than a lecturer-the twelve roles of the teacher. Med Teach. 2000;22(4):334-47.

3. Chickering AW, Gamson ZF. Seven principles for good practice in undergraduate education. Am Assoc High Educ Bull. 1987; 39(7):3-7.

4. Dandekar SP, Maksane SN, McKinley D. A survey validation and analysis of undergraduate medical biochemistry practical curriculum in Maharashtra, India. Ind J Clin Biochem. 2012; 27(1):52-60.

5. Minasian-Batmanian LC, Lingard J, Prosser M. Variation in student reflections on their conceptions of and approaches to learning biochemistry in a first-year health sciences' service subject. Int J Sci Educ. 2006;28(15):1887-904.

6. Zunic L, Skrbo A, Causevic A, Prnjavorac B, Sabanovic Z, Pandza H, Masic I. Role of Laboratory Diagnostic Medical Biochemistry Services -analysis of Requirements for the Laboratory Test in the 
Laboratory of Primary Health Care Center. Med Arh. 2011;65(4):202-6.

7. Plebani M. Charting the course of medical laboratories in a changing environment. Clin Chim Acta. 2002;319(2):87-100.
8. Panteghini M. The future of laboratory medicine: understanding the new pressures. Clin Biochem Rev. 2004;25(4):207-15.

9. Kilpatrick ES. The Hitchhiker's guide to research in clinical biochemistry. Clin Biochem Rev. 2010;31(1):25-8. 